\title{
Quantitative Structure-Activity Relationships for Predicting the Joint Toxicity of Substituted Anilines and Phenols to Algae
}

\author{
G. H. Lu $\cdot$ C. Wang $\cdot$ Z. Y. Tang $\cdot$ X. L. Guo
}

Published online: 7 May 2008

(C) Springer Science+Business Media, LLC 2008

Erratum to: Bull Environ Contam Toxicol (2007)

78:73-77

DOI 10.1007/s00128-007-9005-1

Due to a problem in the production process this article was published twice as DOI 10.1007/s00128-007-9005-1 in
Bull Environ Contam Toxicol (2007) 78:73-77 and as DOI 10.1007/s00128-007-9070-5 in Bull Environ Contam Toxicol (2007) 78:107-111.

Springer apologizes for any confusion caused by the duplicate publication.

The online version of the original article can be found under doi: 10.1007/s00128-007-9005-1.

G. H. Lu · C. Wang $(\bowtie) \cdot$ Z. Y. Tang $\cdot$ X. L. Guo

Key Laboratory for Integrated Regulation and Resources

Exploitation on Shallow Lakes, Ministry of Education,

College of Environmental Science and Engineering,

Hohai University, Nanjing 210098,

People's Republic of China

e-mail: ghlucc@sina.com 